\title{
Inadequate post-partum screening for type 2 diabetes in women with previous gestation diabetes mellitus: a retrospective audit of practice over 17 years
}

\author{
Rebecca Ward ${ }^{1}$, Anthony Fryer ${ }^{2}$, Fahmy Hanna ${ }^{1}$, Nathaniel Spencer ${ }^{1}$, Madia Mahmood ${ }^{1}$, \\ Pensee $\mathrm{Wu}^{2}$, Adrian Heald ${ }^{3}$, and Christopher Duff ${ }^{1}$ \\ ${ }^{1}$ University Hospitals of North Midlands NHS Trust \\ ${ }^{2}$ Keele University \\ ${ }^{3}$ Salford Royal Hospitals NHS Trust
}

October 24, 2020

\begin{abstract}
Introduction: Women with gestational diabetes (GDM) are at greatly increased risk of type 2 diabetes (T2DM). The UK guidance recommends screening for T2DM at around 6 weeks post-partum and annually thereafter. We evaluated conformity to this guidance in two separate time periods. Methods: The proportion of tests performed within guidance was assessed using longitudinal plasma glucose and glycated haemoglobin data in two cohorts (1999-2007, $\mathrm{n}=251 ; 2015-2016, \mathrm{n}=260)$ from hospital records on women previously diagnosed with GDM. Results: In the 1999-2007 and 2015-2016 cohorts, 59.8\% and 35.0\% of women had the recommended post-partum testing, respectively ( $\mathrm{p}<0.001$ ); just $13.5 \%$ and $14.2 \%$, respectively, underwent the first annual test on time. During long-term follow-up of the 1999-2007 cohort (median follow-up: 12.3 years), the proportion of women tested in any given year averaged $34.2 \%$ over a 17 -year period; there was a progressive decline in the proportion of women receiving a yearly test with time since delivery $(\mathrm{p}=0.002)$. Over the follow-up period, 85 women from the 1999-2007 cohort developed blood test results in the diabetic range with a median time to presumed DM diagnosis of 5.2 years (range 0.11-15.95 years). Kaplan-Meier analysis showed that $18.8 \%$ of women had blood test results in the diabetes range by 5 years and $37.8 \%$ by 10 years post-partum. Conclusions: Despite high profile guidelines and a clear clinical rationale to screen women with a past diagnosis of GDM, many women did not receive adequate screening for T2DM, both in the short- and long-term. This suggests alternative approaches are needed to ensure effective follow-up of this high-risk group. To have an impact, interventions need to be tailored to a young, generally healthy group in which traditional approaches to follow-up may not be best suited.
\end{abstract}

\section{Hosted file}

Ward et al GDM paper IJCP main text.pdf available at https://authorea.com/users/369846/ articles/488660-inadequate-post-partum-screening-for-type-2-diabetes-in-women-withprevious-gestation-diabetes-mellitus-a-retrospective-audit-of-practice-over-17-years

\section{Hosted file}

Ward et al GDM Figure 1.pptx available at https://authorea.com/users/369846/articles/488660inadequate-post-partum-screening-for-type-2-diabetes-in-women-with-previous-gestationdiabetes-mellitus-a-retrospective-audit-of-practice-over-17-years 

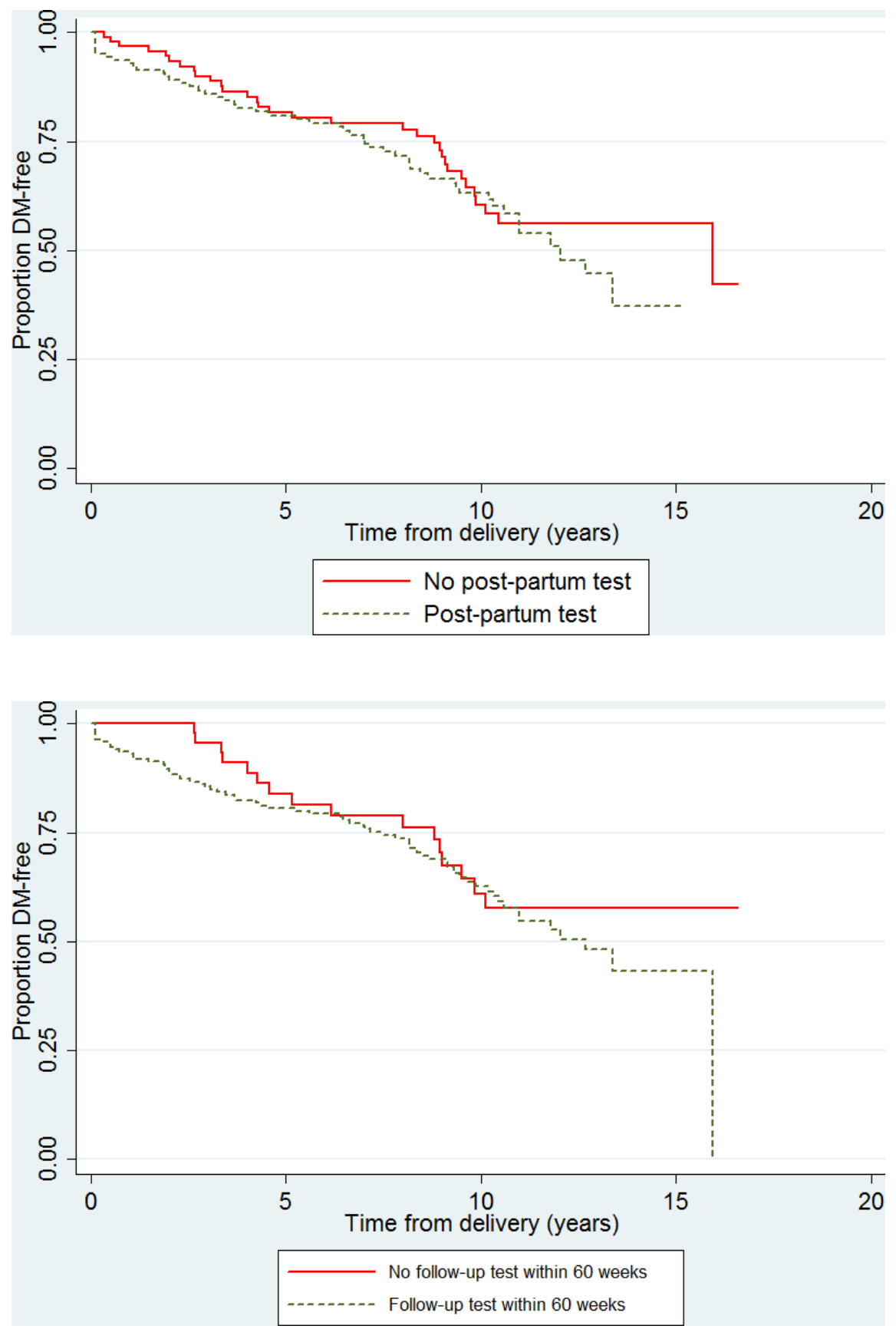